\title{
After the Crash: Oil Price Recovery and LNG Project Viability
}

\author{
Uyiosa Omoregie \\ Corporate Planning Department, Brass LNG Ltd., Lagos, Nigeria \\ Email: uyiosa.omoregie@brasslng.com
}

How to cite this paper: Omoregie, U. (2019) After the Crash: Oil Price Recovery and LNG Project Viability. Natural Resources, 10, 179-186.

https://doi.org/10.4236/nr.2019.105012

Received: April 12, 2019

Accepted: May 27, 2019

Published: May 30, 2019

Copyright $\odot 2019$ by author(s) and Scientific Research Publishing Inc. This work is licensed under the Creative Commons Attribution International License (CC BY 4.0).

http://creativecommons.org/licenses/by/4.0/

\begin{abstract}
Are liquefied natural gas (LNG) projects currently viable? LNG projects viability has been shown to be sensitive to crude oil price. Crude oil prices fell below the 2009-2014 five-year average in early September 2014. The drastic fall in price was from a monthly peak of $\$ 112$ per barrel (bbl) in June 2014, falling to $\$ 62 / b b l$ in December. Since 2016 the oil and gas market has gone through a period of rebalancing, resulting in modest recovery in prices. Oil price recovery reached a peak of $\$ 85 / \mathrm{bbl}$ in October 2018. Gas prices have also achieved similar modest price recovery. The industry has now entered what appears to be an expansion phase: The five largest international oil companies exceeded expectations for 2018. A window of opportunity may exist for new LNG projects to commence production in anticipation of an undersupplied market (2025-2035). Viability of new LNG projects will depend on future oil price. LNG projects can provide long and stable dividends for shareholder companies, certain risks found in tight oil and upstream projects are absent.
\end{abstract}

\section{Keywords}

Oil, Gas, Price, LNG, Viability

\section{Introduction}

The headline news in the oil and gas industry for 2014 was the oil price collapse. LNG projects viability is sensitive to the crude oil price [1]. Since 2014 there has been a modest rebound in oil and gas price, but with a lot of volatility [2]. The industry may now be entering an expansion phase. The oil and gas industry has always functioned in cycles since the 1860s and the volatility experienced in the past few years are historically the norm in the industry, not an anomaly.

Boom-bust-rebound-reversal characterizes this industry. McNally [3] presents 
oil price time series (monthly) from 1859 to 2015 that reveal volatility in oil price. McNally also presents global spare oil production capacity from 1955-2015:

Extreme volatility... is an intrinsic feature of the oil industry. Historically, oil prices have experienced multi-decade eras of relative stability and wild, boom-bust gyrations... recent fluctuations mark a return of a free and unfettered market for crude oil, and as a consequence boom-bust oil prices are making a return after eight decades [3].

Changes in oil and gas prices since the crash of 2014 are revealed in the beginning of this paper. What follows is a discussion of rebalancing ongoing in the industry. The UN Paris Agreement is discussed with its implications for oil and gas projects, and LNG in particular. Towards the end of the paper are projections for the oil price and LNG supply and demand, with implications for LNG projects viability. The paper concludes with discussion about the profitably of international oil companies in 2018 (mostly due to the oil price rebound) and the implications for LNG projects.

\section{Oil Price Crash of Mid-2014}

As global crude oil production exceeded demand, Brent crude oil prices fell in Q4 2014. In June 2014 the oil price achieved a monthly peak of $\$ 112$ per barrel (bbl) but crashed to $\$ 62 /$ bbl in December 2014 (Figure 1).

Crude oil prices fell below the five-year average in early September and slipped well below the five-year range in November and December (Figure 2).

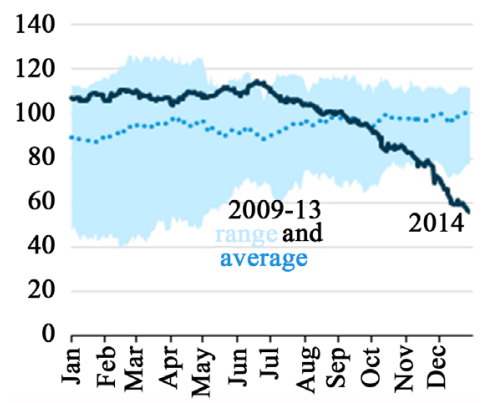

Figure 1. Brent crude oil price in 2014 (USD/barrel) [2].

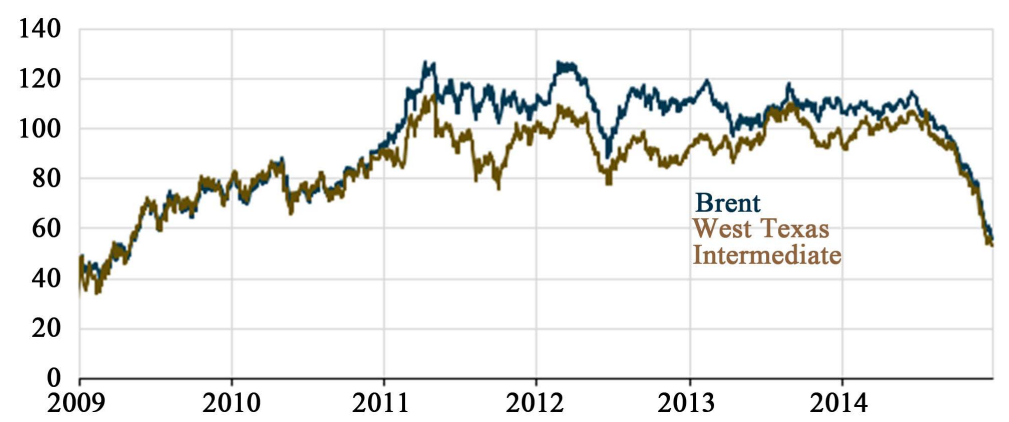

Figure 2. Crude oil prices in 2009-2014 (USD/barrel) [2]. 


\section{Oil and Gas Prices Since 2014}

Brent crude oil prices continued to plummet in 2015 with a modest recovery since 2016, showing a rebalancing of the market. Brent crude oil price reached a 4 -year high of $\$ 85 / \mathrm{bbl}$ in October 2018 (Figure 3).

Global gas prices plummeted around 2014-2016 and a modest recovery has occurred since 2016 (Figure 4).

\section{Moving Towards a Rebalancing of the Market}

There has been a move towards the rebalancing of the oil and gas market since the crash in prices of 2014. According to Kemp [5], the industry's cyclical indicators (production, consumption, stocks, investment, employment, prices, and costs) show that an upward swing is slowly but surely in progress for the short to medium term. A gradual increase in prices and drilling activity since 2015 centred mostly in the shale plays of North America.

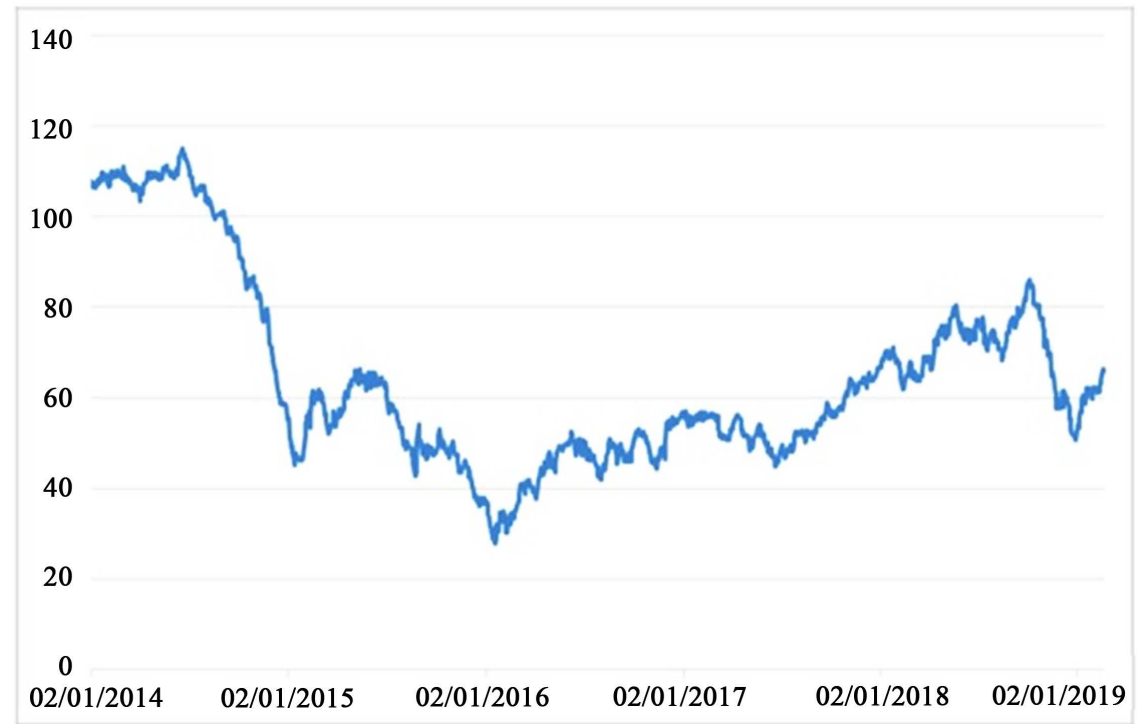

Figure 3. Brent crude oil prices 2014-2019 (USD/barrel) [2].

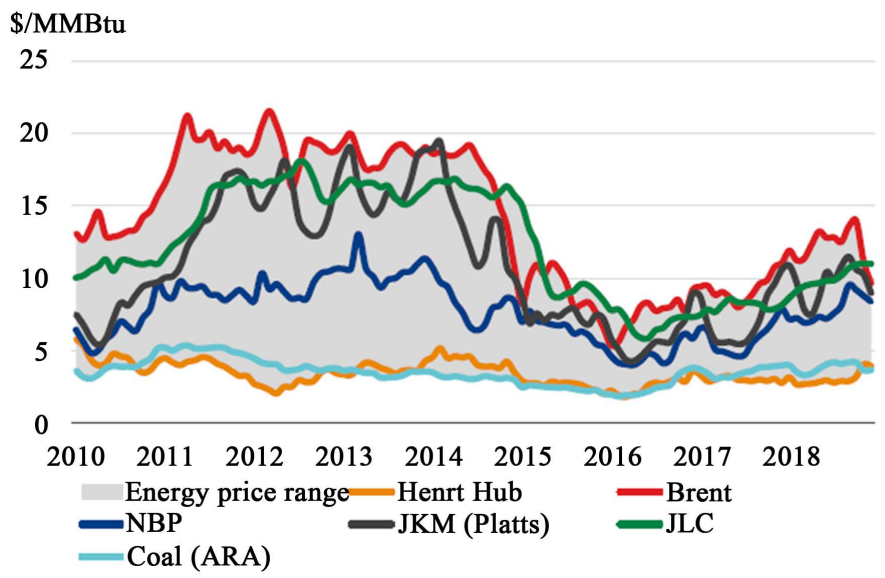

Figure 4. 2014-2019 Global gas and energy prices trend (USD/MM BTU) [4]. 


\section{United Nations Framework Convention on Climate Change}

The major global policy intervention since the oil price crash, relevant to the oil and gas industry, is the United Nations Paris Agreement. To limit the risks and effects of global climate change, in 2015 an international agreement was reached to prevent global average temperate rise from exceeding $2^{\circ} \mathrm{C}$ above pre-industrial levels and limit any increase to $1.5^{\circ} \mathrm{C}$. Known as the "Paris Agreement", this agreement within the United Nations Framework Convention on Climate Change (UNFCCC) will commence in 2020 aimed at greenhouse-gas-emissions mitigation, adaptation, and finance. Representatives of 196 countries adopted the agreement on 12 December 2015 and each country must determine, plan and report (regularly) on its global warming mitigation efforts.

A climate accord such as the Paris Agreement will surely impact oil and gas production, if producer and consumer countries take the agreement seriously. Oil reserves may become "stranded" or "unburnable" when there's a commitment to limit global temperature rise to $2^{\circ} \mathrm{C}$ or less. This is a very different scenario from the "peak oil" concern that was pushed in the industry a few decades ago. It no longer appears that oil supply will "peak" any time soon [6]. The concern now is that oil demand may already have peaked. Scheitrum et al. [7] state that energy efficiency and government regulation have already constrained oil demand (by limiting oil use) in OECD countries. There is also the concept of a "remaining global 'carbon budget' associated with the probability of successfully keeping the global temperature rise below a certain level" [8]. But, McGlade and Ekins [8] also state that "under the $2^{\circ} \mathrm{C}$ scenario, gas plays an important part in displacing coal from the electrical and industrial sectors." Gas is widely acknowledged to be a "cleaner" fossil fuel, a "transitional" fuel on the road to cleaner energy. In a widely read journal article, the US President, Barack Obama [9], acknowledged gas as part of the "irreversible momentum of clean energy":

The American electric-power sector-The largest source of GHG emissions in our economy-Is being transformed, in large part, because of market dynamics. In 2008 , natural gas made up $\sim 21 \%$ of U.S. electricity generation. Today, it makes $\sim 33 \%$, an increase due almost entirely to the shift from higher-emitting coal to lower-emitting natural gas, brought about primarily by the increased availability of low-cost gas due to new production techniques.

\section{LNG Demand and Supply Projection}

According to the Shell LNG Outlook [4], "there's a growing recognition of the role of gas and LNG as the world tackles poor air quality and climate change." The outlook estimates that gas will supply the largest share of energy demand growth, supplying over $40 \%$ of additional demand by 2035 . LNG is still the fastest-growing gas supply source, with a compound annual growth rate of $4 \%$ a year projected till 2035. LNG demand is expected to continue around the world especially in Asia and Europe. In 2018 global LNG delivered volumes soared to 
319 million tonnes. Japan remained the world's largest LNG importer in 2018, followed by China. Based on demand projections, a supply shortage may develop in the mid-2020s unless new LNG projects start production before then (Figure $5)$.

\section{Oil Price Projection}

The U.S. Energy Information Administration's (EIA) 2019 projections in its Annual Energy Outlook [2] involve three different cases for Brent crude oil price:

1) In the High Oil Price case, the price of Brent crude oil, in 2018 dollars, is projected to reach $\$ 212$ per barrel by 2050 .

2) In the Reference case the price of Brent crude oil, in 2018 dollars, is projected to reach $\$ 108$ per barrel by 2050 .

3) In the Low Oil Price case the price of Brent crude oil, in 2018 dollars, is projected to be $\$ 50$ per barrel by 2050 .

The EIA projects the average oil price for the 20 years (2018-2038) will be $\$ 87 /$ bbl (Figure 6).

\section{LNG Project Sensitivity to Oil Price (Figure 7)}

See Figure 7.

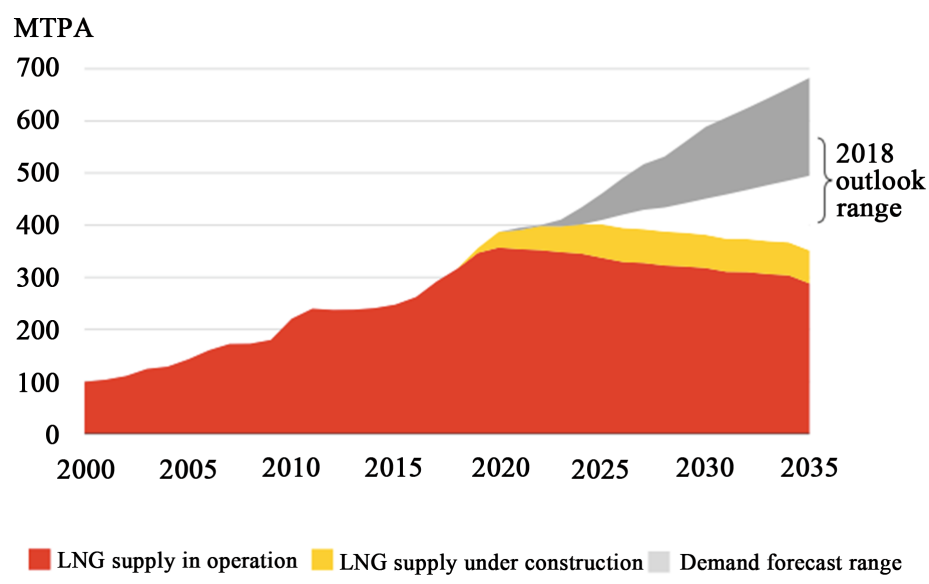

Figure 5. Emerging LNG supply-demand gap [4].

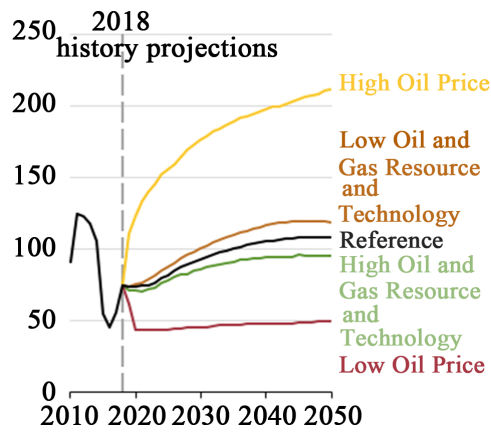

Figure 6. Brent crude oil price projection to 2050 (USD 2018) [2]. 


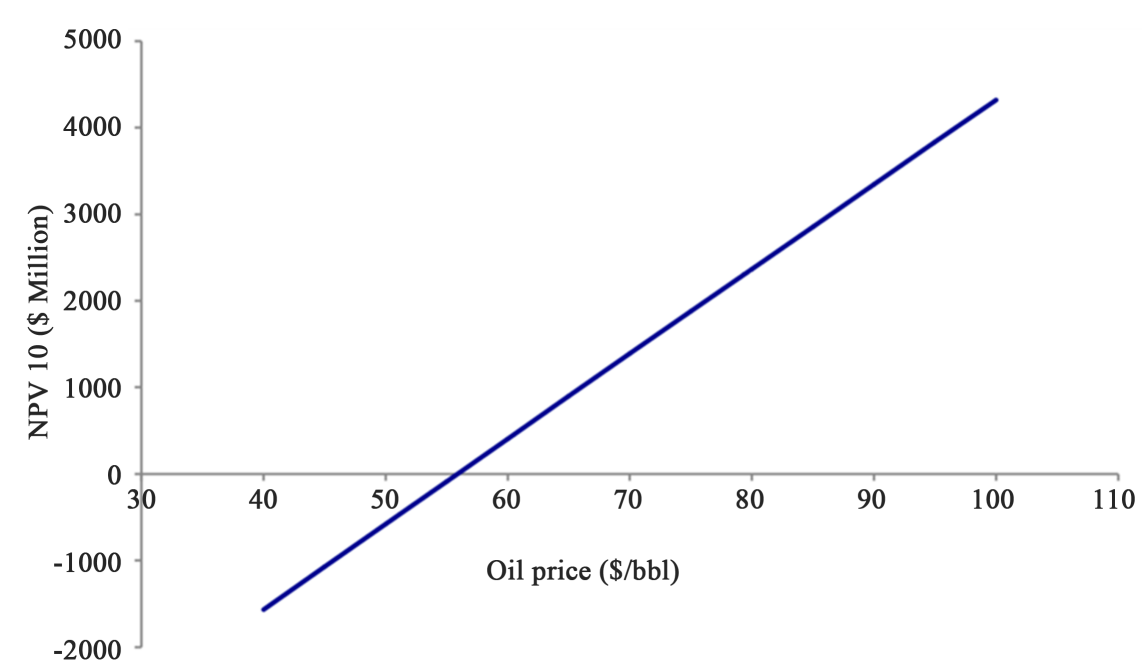

Figure 7. LNG project sensitivity to oil price. Break even oil price of $\$ 56 / \mathrm{bbl}$ [1].

\section{Profitability}

\subsection{International Oil Companies Stellar 2018 Earnings}

Gilblom and Katakey [10] reveal that the five largest international oil companies (Exxon, Shell, Chevron, Total and BP) exceeded expectations for 2018. This was due to a more disciplined business approach and a focus on the lowest cost barrels during a period of market volatility. The combined cash flow of the five supermajor oil companies is the highest for at least eight years (Figure 8).

\subsection{LNG Projects Funds Flow Profile Compared with Other Oil and Gas Projects}

A comparison was made between the funds flow from operations (FFO) profile for LNG projects and various North American oil and gas projects ranging from mining to light oil [11]. Cash flows from mining projects consist of large upfront initial investment (trough in the cash flow chart) then payout increases over the years. The dividend-like payouts are long in duration and stable. Mining projects require low OPEX and there is very little decline over the years compared with tight oil and offshore projects. LNG projects in this respect have more in common with mining projects than upstream or tight oil projects. Reservoir risk and recovery factor are not issues that LNG projects have to deal with (Table 1, Figure 9).

\section{Conclusion}

The outlook for the LNG market is bright with a projected annual growth rate of $4 \%$ until 2035. Currently, global LNG supply is meeting global demand because new projects came on stream within the past decade. However, because demand is projected to surpass supply in the period 2025-2035, there is a window of opportunity for new LNG projects to achieve FID and come on stream within the next seven years or so. This presents an opportunity for LNG projects. 
Cash flow from operations

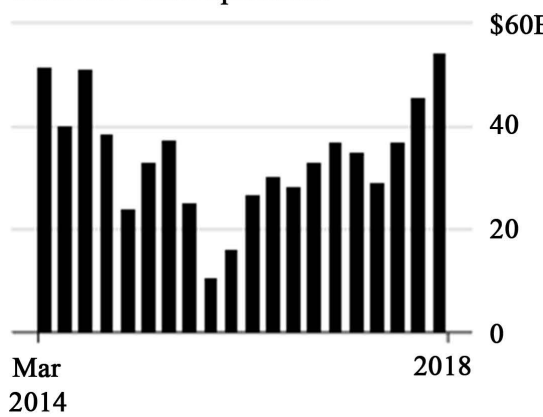

Adjusted net income

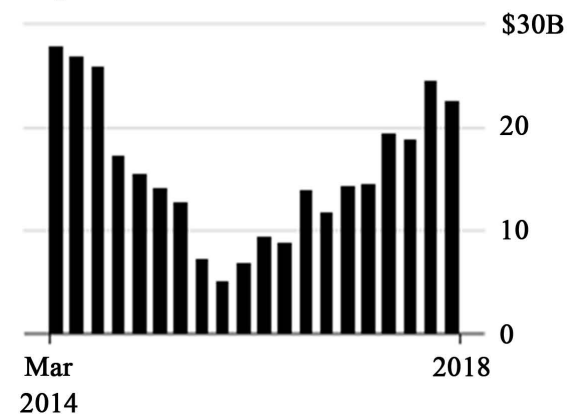

Figure 8. Five supermajor oil companies' cash flow and adjusted income (2014-2018) [10].
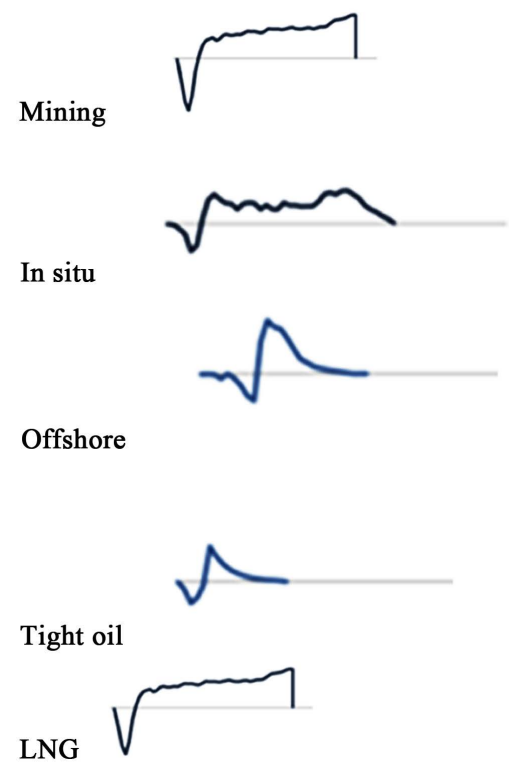

Figure 9. Illustrative annual (FFO) profile for some oil and gas projects [11].

Table 1. Comparison of oil and gas projects [11].

\begin{tabular}{ccccccc}
\hline $\begin{array}{c}\text { Project } \\
\text { Type }\end{array}$ & $\begin{array}{c}\text { Initial } \\
\text { Capital }\end{array}$ & $\begin{array}{c}\text { Decline } \\
\text { Rate }\end{array}$ & $\begin{array}{c}\text { Sustaining } \\
\text { Cost }\end{array}$ & $\begin{array}{c}\text { Operating } \\
\text { Cost }\end{array}$ & $\begin{array}{c}\text { Reservoir } \\
\text { Risk }\end{array}$ & $\begin{array}{c}\text { Recovery } \\
\text { Factor }\end{array}$ \\
\hline Mining & High & V. Low & V. Low & Medium & V. Low. & V. High \\
In Situ & Medium & Low & Low & Low & Low & High \\
Offshore & High & High & Medium & V. Low & Medium & Medium \\
Tight Oil & Low & V. High & High & Medium & High & Low \\
LNG & High. & N/A. & Low & Medium & N/A & N/A \\
\hline
\end{tabular}

Gas has received renewed focus from policy makers around the world after the 2015 UN Paris Agreement on climate change was achieved. The rebalance of the oil and gas industry is underway, accompanied with a steadfast recovery in oil price. The largest international oil companies achieved outstanding financial and operational results for 2018 due to the positive changes underway in the industry. The industry's cycle has entered an expansion phase which should trigger 
a renewed focused towards taking final investment decisions for LNG projects. The EIA projected average oil price of $\$ 87 /$ bbl for 20 years $(2018-2038)$ is above the breakeven price for LNG project viability, which is justification for such projects.

\section{Conflicts of Interest}

The author declares no conflicts of interest regarding the publication of this paper.

\section{References}

[1] Omoregie, U. (2015) The Oil Price Crash of 2014: Implications for a Multi-Billion Dollar LNG Project. Natural Resources, 6, 577-582.

https://doi.org/10.4236/nr.2015.612055

[2] U.S. Energy Information Administration. https://www.eia.gov

[3] McNally, R. (2017) Crude Volatility: The History and the Future of Boom-Bust Oil Prices. Columbia University Press, New York. https://doi.org/10.7312/mcna17814

[4] Shell (2019) Shell LNG Outlook. https://www.shell.com/energy-and-innovation/natural-gas/liquefied-natural-gas-ln g/lng-outlook-2019.html

[5] Kemp, J. (2017) Macroeconomic Risks for the Oil Industry. https://www.reuters.com/article/us-oil-business-cycle-kemp/macroeconomic-risks-f or-the-oil-industry-kemp-idUSKBN1AK23O

[6] Jaffe, A. (2016) The Role of the US in the Geopolitics of Climate Policy and Stranded Oil Reserves. Nature Energy, 1, 1-4. https://www.nature.com/articles/nenergy2016158 https://doi.org/10.1038/nenergy.2016.158

[7] Scheitrum, D., Jaffe, A. and Fulton, L. (2016) Changing Oil Market Fundamentals and Implications for OPEC Production Strategy. IAEE Energy Forum. https://steps.ucdavis.edu/wp-content/uploads/2017/05/2016-UCD-ITS-RP-16-24.pdf

[8] McGlade, C. and Ekins, P. (2015) The Geographical Distribution of Fossil Fuels Unused When Limiting Global Warming to $2^{\circ} \mathrm{C}$. Nature, 517, 187-190.

https://www.nature.com/articles/nature14016 https://doi.org/10.1038/nature14016

[9] Obama, B. (2017) The Irreversible Momentum of Clean Energy. Science, 355, 126-129. https://science.sciencemag.org/content/355/6321/126 https://doi.org/10.1126/science.aam6284

[10] Gilblom, K. and Katakey, R. (2019) What Crash? Big Oil Proves the Crude Oil Price Is Just a Number. https://www.bloomberg.com/news/articles/2019-02-07/what-crash-big-oil-proves-t he-crude-price-is-just-a-number

[11] Somanchi, K. (2019) Strategic Impetus of Investing in LNG Projects. Gastech Insights.

https://gastechinsights.com/article/strategic-impetus-of-investing-in-lng-projects 